\title{
Can NOTSS methodology improve ACGME competencies when combined with simulation-based education?
}

\section{Eugene Tuyishime* William D. Watson and Edward Dominguez}

OhioHealth Learning, Riverside Methodist Hospital, Columbus, Ohio, USA

${ }^{*}$ Corresponding author at: 3440 Olentangy River Road, Columbus, OH 43202, USA. Email: tuyishime36@gmail.com

Date accepted for publication: 8 June 2021

\section{Abstract}

Background: An expanding neck hematoma after thyroidectomy is a rare complication requiring urgent airway management and potential bedside evacuation before definitive surgical management. During our review of the literature, no evidence of an adequate teaching method for the management of post-thyroidectomy hematoma for novice learners was found. This study aimed to determine if Non-Technical Skills for Surgeons (NOTSS) methodology can improve Accreditation Council for Graduate Medical Education (ACGME) competencies when combined with simulation-based education. Methods: This study used a randomized controlled study design to evaluate the performance of ACGME competencies among two study groups. The intervention group participated in a 30-min NOTSS lecture and a 25-min simulation scenario, and the control group participated in a 25-min simulation scenario only. A follow-up scenario was conducted to evaluate residents' performance in neck hematoma management. The study's primary outcome was participants' total performance scores on the six ACGME competencies (patient care, medical knowledge, interprofessional and communication skills, professionalism, practice-based learning and improvement, and systembased practice). Results: This study did not show a statistically significant difference in the total performance scores on the six ACGME competencies among the two study groups $(35.2 \pm 3.62$ versus $31.7 \pm 3.75 ; P=0.077)$. In addition, there were no statistically significant differences in the performance scores for any of the six ACGME competencies. Conclusions: This study failed to confirm our hypothesis that NOTSS methodology can improve ACGME competencies when combined with simulation-based education. A study with a bigger sample size and a higher number of observable events may be necessary to have the power to detect a statistically significant difference. In addition, there was a long delay in the study due to the Coronavirus-19 pandemic. Less retention of skills in the intervention group may have changed the results of the study. Some of the later evaluation scenarios were done under the rules of social distancing which could alter the efficacy of the teaching.

Keywords: neck hematoma; non-technical skills; simulation-based education

\section{Introduction}

Non-technical skills (NTS), such as communication, team working, and task coordination, have been shown to improve patient safety. ${ }^{1} \mathrm{Up}$ to $70 \%-80 \%$ of adverse events in health care are associated with errors in NTS. ${ }^{2}$ The NonTechnical Skills for Surgeons (NOTSS) framework describes behavior markers for NTS in surgery, which allow surgeons to practice safely and minimize errors. ${ }^{3,4}$ This NOTSS framework focuses on four key essential NTS: situation awareness, decision-making, teamwork and communication, and leadership. ${ }^{3}$ In addition, the NOTSS framework has been validated for teaching and evaluating essential NTS for practicing safe surgery to a multidisciplinary team of novice learners including surgery residents and nurses. ${ }^{3-8}$ Furthermore, the NOTSS framework has been shown to improve team performance in the operating room especially during a crisis. ${ }^{9}$

Neck hematoma is a rare postoperative event with an incidence between $0.53 \%$ and $1.43 \% .{ }^{11-13}$ A review of 150,012 patients found a post-thyroidectomy hemorrhage incidence of $1.25 \%$ with higher mortality in this group $(1.34 \%$ versus $0.32 \%) .{ }^{11}$ General surgery residents may finish a residency without being exposed to this event clinically. Simulationbased education can be an adequate solution to ensure that 
residents are exposed to this situation. A simulated case of post-thyroidectomy hematoma was used in this study to teach management of neck hematoma.

The ideal treatment plan for postoperative neck hematoma consists of quick recognition, adequate evaluation of airway compromise, release of sutures, evacuation of hematoma, and reoperation. ${ }^{18}$ Cervical hematoma presents as a large, dense, firm, immobile anterior or lateral cervical swelling under the incision. It may quickly lead to airway compromise with signs of upper airway obstruction such as dyspnea, stridor, and hoarseness; therefore, quick recognition and appropriate management are important to avoid poor outcome. ${ }^{18}$ Most evacuations are done before intubation in the operating room ( $79 \%$ versus $21 \%)$ to decrease the risk of a difficult airway. ${ }^{18}$ Simulation-based education has been used previously to teach rare events to novice learners with a focus on both technical skills and NTS. ${ }^{19-26}$

During our review of the literature, no evidence was found of an adequate teaching method for the management of post-thyroidectomy hematoma for novice learners. Therefore, to address that gap, our study aimed to determine if Non-Technical Skills for Surgeons (NOTSS) methodology can improve Accreditation Council for Graduate Medical Education (ACGME) competencies when combined with simulation-based education. The six ACGME competencies (patient care, medical knowledge, interprofessional and communication skills, professionalism, practice-based learning and improvement, and system-based practice) were assessed after NOTSS education. ${ }^{10}$

\section{Hypothesis}

We hypothesized that the NOTSS methodology can improve ACGME competencies when combined with simulationbased education.

\section{Methods}

\section{Study design}

This study used a randomized-control study design to evaluate ACGME competencies of participants after a simulated case of post-thyroidectomy hematoma. The data collection tool was developed using a modified Delphi method. After completing a literature review, an initial draft of 27 questions was sent by email to five experts who gave feedback about which questions should be removed from the final data collection tool. We than organized one in-person meeting to achieve consensus and to finalize the data collection tool of 22 essential questions (Appendix 1). The team included four surgeons and one anesthesiologist. To be considered an expert, the participants had to be board-certified in surgery or anesthesia and involved in teaching surgical residents.

\section{Description of the intervention}

The investigators proposed the following structure. (1) The intervention group took part in a 30 -min NOTSS lecture ${ }^{33}$ and a 25 -min simulation scenario (10 $\mathrm{min}$ for the scenario and 15 min for debriefing; Appendix 2). The NOTSS lecture covers four essential NTS for surgeons, including situation awareness, decision-making, communication and teamwork, and leadership. This content was presented to the intervention group by a trained NOTSS instructor. (2) The control group took part in a 25 -min simulation scenario (10 $\mathrm{min}$ for the scenario and $15 \mathrm{~min}$ for debriefing).

The simulation scenario allowed learners to apply their knowledge to a situation similar to a real-world experience and practice their NTS and technical skills. During debriefing, the intervention and control groups received all components of the NOTSS course.

\section{Study participants}

All general surgery residents (post-graduate year [PGY] 1-4) were eligible to attend this post-thyroidectomy simulationbased training. PGY 5 surgery residents were excluded from this study.

\section{Study conduct}

A consent form was provided to eligible study participants during weekly morning meetings. One co-investigator reviewed the information on the form with potential participants. After an opportunity to address questions, written consent was obtained. The post-thyroidectomy simulationbased training was conducted by a team of two experienced surgeons, one anesthesiologist, and one experienced nurse. The scenario required the study participant to function as an on-call resident. A low-fidelity trainer/manikin was used to simulate the patient findings, and supporting roles in the scenario were played by colleagues who followed pre-determined standardized scripts.

\section{Outcome}

The study's primary outcome was the participants' total performance scores on the six ACGME competencies (patient care, medical knowledge, interprofessional and communication skills, professionalism, practice-based learning and improvement, and system-based practice).

All scenarios were audio-video recorded in blinded fashion. Two independent raters (surgeons) reviewed all videos and, using a pre-determined data collection tool (Appendix 1), scored each participant's performance. The raters did not know the participants and inter-rater reliability was 
calculated. Raters were educated on the data collection tool by the research team.

\section{Data management}

After giving consent, each participant was provided with a unique identifying number. This number was used for all data analysis and storage. The principal investigator had sole access to the demographic information as it related to the unique identifying number. Study materials were kept in a locked file in the office of the principal investigator. Data materials will be kept for a period of 5 years.

\section{Statistical analysis}

The sample size was calculated a priori for the mean difference in average ACGME competencies between the intervention and control groups. Previous literature determining NTS scores demonstrated an average mean difference of 2 between scores and a standard deviation (SD) of 3.1 (standard deviation of the mean difference [SMD], 0.645). ${ }^{28}$ Assuming a two-tailed test with $\alpha=0.05,80 \%$ power, an effect size with $\mathrm{SMD}=0.645$, and $\mathrm{SD}=3.1,16$ participants were required (eight participants per group) to detect a difference in overall average ACGME score of $20 \%$ between the control and intervention arms.

Two independent raters rated the performance of the participants in each scenario according the ACGME competencies. Raters were blinded about the participants' level of education and study group. Scores were assigned for each ACGME competency, summed to provide an overall average ACGME score (0-44 scale) (Appendix 2). Data from both raters were averaged and used as a total for the analysis.

Inter-rater reliability (IRR) was calculated using a variant of kappa known as Gwet's AC1 (category scores) and an absolute agreement intraclass correlation (total score). ${ }^{29}$ Hypotheses were tested using Friedman's ANOVA and the Durbin-Conover method for post hoc tests with the jmv package in $\mathrm{R}$ statistical software (https://CRAN.R-project. org/package.jmv). All comparisons were made using the Mann-Whitney test. Data were visualized using combined box and stacked dot plots. Missing data were handled using listwise deletion before hypothesis testing, but all data are presented in plots.

\section{Results}

This study included 18 residents from PGY 1-4. All eligible residents participated in the study. There was no difference in the number of residents with regard to level of education among the control and intervention arms (Table 1). The IRR was evaluated using intraclass correlation. Two-rater
Table 1. Residents' education level and the study groups ( $N=18)$

\begin{tabular}{llll}
\hline & $\begin{array}{l}\text { NOTTS combined with } \\
\text { SBE (intervention } \\
\text { group), } \mathbf{n}\end{array}$ & $\begin{array}{l}\text { SBE alone } \\
\text { (control } \\
\text { group), } \mathbf{n}\end{array}$ & P value \\
\hline PGY 1 & 3 & 2 & 0.94 \\
PGY 2 & 2 & 3 & \\
PGY 3 & 2 & 2 & \\
PGY 4 & 2 & 2 \\
Total & 9 & 9 \\
\hline
\end{tabular}

IRR was performed at the sub-scale level and ranged from 0.31 to 0.78 with an average inter-rater reliability of 0.52 .

This study did not show a statistically significant difference in the total performance scores for the six ACGME competencies (patient care, medical knowledge, interprofessional and communication skills, professionalism, practice-based learning and improvement, and system-based practice) among the two study groups $(35.2 \pm 3.62$ versus $31.7 \pm 3.75 ; P=0.077$ ) (Table 2). There was no statistically significant increase in performance score for any of the six ACGME competencies, however there was a trend for higher scores in the intervention group (Table 3, Fig. 1). There was no statistically significant difference in the performance score for any of the six ACGME competencies by PGY levels (Table 4).

\section{Discussion}

This study did not show a statistically significant difference in the total performance scores for the six ACGME competencies (patient care, medical knowledge, interprofessional and communication skills, professionalism, practice-based learning and improvement, and system-based practice) among the two study groups. The results of this study failed to confirm our hypothesis that NOTSS methodology can improve ACGME competencies when combined with simulation-based education.

This study showed a different result in comparison with other studies that demonstrated a positive impact on NTS and an improvement in the performance of different surgical teams after a NOTSS course. ${ }^{3-9}$

The reason for this difference may be due to the fact that our study had a small sample size $(\mathrm{N}=18)$ and a low number of observations (nine for each study group). Other NOTSS studies had higher numbers of observations (up to 43 observations). ${ }^{6}$ A study with bigger sample size 
Table 2. Residents' performance according to ACGME competencies

ACGME competencies Target actions: resident has

NOTTS-SBE
(mean, SD)

SBE alone

$P$ value

ACGME competenci

Target actions: resident has

(mean, SD)

Step 1: Identification of posthyroidectomy hematoma

Interpersonal and communication skills

1. performed introductions

$1.33(0.50)$

$1.50(0.56)$

$2.00(0.00)$

0.490

2. received handover

$2.00(0.00)$

$1.56(0.77)$

NA

Patient care

3. performed focused physical examination of

$1.78(0.51)$

$1.83(0.35)$

0.576

4. identified hematoma

$1.89(0.22)$

$1.28(0.80)$

Interpersonal and communication skills

5. called for help (anesthesiologist and surgeon)

6. called for resuscitation cart

$1.56(0.39)$

0.952

$1.61(0.49)$

$1.83(0.25)$

0.393

Medical knowledge

7. informed team (nurse, anesthesiologist, and

$1.56(0.39)$

$1.33(0.75)$

0.118

surgeon) about the management plan

Step 2: Management of posthyroidectomy hematoma

Patient care

Interpersonal and communication skills

Professionalism

Practice-based learning and improvement

System-based practice

Total score $(\max 44)$
8. removed dressing and Steristrips

9. released skin sutures

10. released deep sutures

11. evacuated hematoma

12. placed temporary packing

13. considered intubation

14. informed operating room (OR) of take back

15. exchanged information with the team when

the patient's oxygen saturation dropped

16 . worked effectively with the team when the patient's oxygen saturation dropped

17. listened attentively to the stated needs of information provided by the team during the crisis

18. informed the attending surgeon of situation 19. demonstrated respect and sensitivity to anesthesia regarding desaturation during difficult airway management (if applicable)

20. recognized that the crisis has been managed

21. verified availability of the $O R$

22 . verified that the team is ready to transport the patient to the OR for definitive management
$1.56(0.58)$

$2.00(0.00)$

$1.50(0.71)$

$1.67(0.43)$

$0.61(0.86)$

$1.72(0.57)$

$1.44(0.77)$

$1.72(0.51)$

$1.50(0.50)$

$1.78(0.51)$

$1.72(0.44)$

$2.00(0.00)$

$1.67(0.43)$

$1.39(0.82)$

$1.00(0.66)$

$35.2(3.62)$
$1.72(0.44)$

$1.94(0.17)$

$1.50(0.66)$

$1.33(0.71)$

$0.22(0.51)$

$1.56(0.77)$

$1.33(0.66)$

$1.61(0.49)$

$1.50(0.50)$

$1.39(0.42)$

$1.56(0.46)$

$1.83(0.35)$

0.431

0.169

$1.44(0.85)$

0.884

$1.22(0.62)$

$0.72(0.51)$

0.521

0.318

31.7 (3.75)

0.077

SBE, simulation-based education.

Table 3. ACGME competencies by intervention group $(N=18)$

\begin{tabular}{llr}
\hline ACGME competencies (maximum score) & NOTTS-SBE (mean) & \multicolumn{1}{c}{$\begin{array}{c}\text { SBE alone (mean) } \\
\text { value }\end{array}$} \\
\hline Patient care (16) & $12.7(1.50)$ & $11.6(1.59)$ \\
Medical knowledge (2) & $1.56(0.39)$ & $1.33(0.75)$ \\
Interpersonal and communication skills (16) & $13.2(1.50)$ & $11.9(1.92)$ \\
Professionalism (4) & $3.72(0.44)$ & $3.39(0.74)$ \\
Practice-based learning and improvement (2) & $1.67(0.43)$ & 0.711 \\
System-based practice (4) & $2.39(1.45)$ & 0.330 \\
\end{tabular}

SBE, simulation-based education. 
(a) Patient care

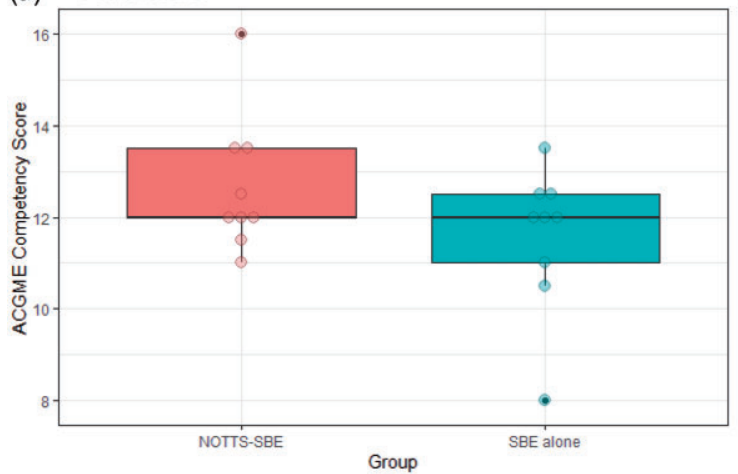

(c) Interpersonal and communication skills

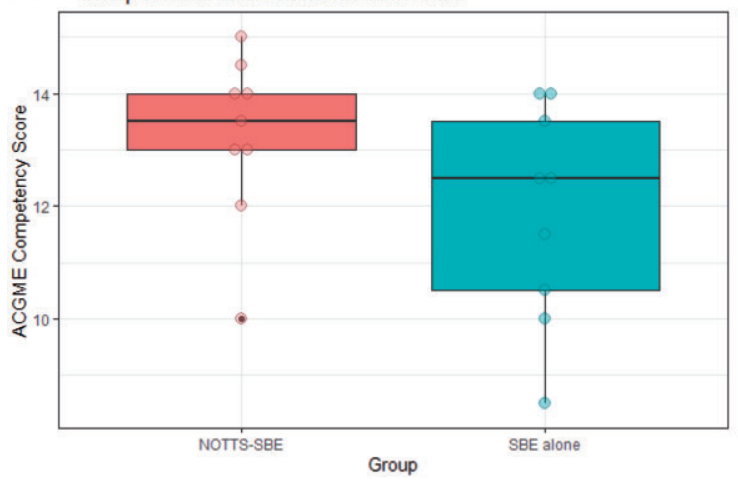

(e) Practice-based learning and improvement

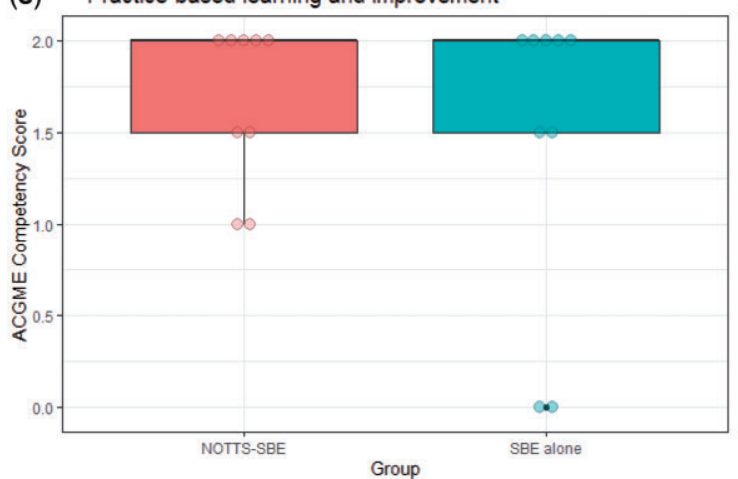

(b) Medical knowledge

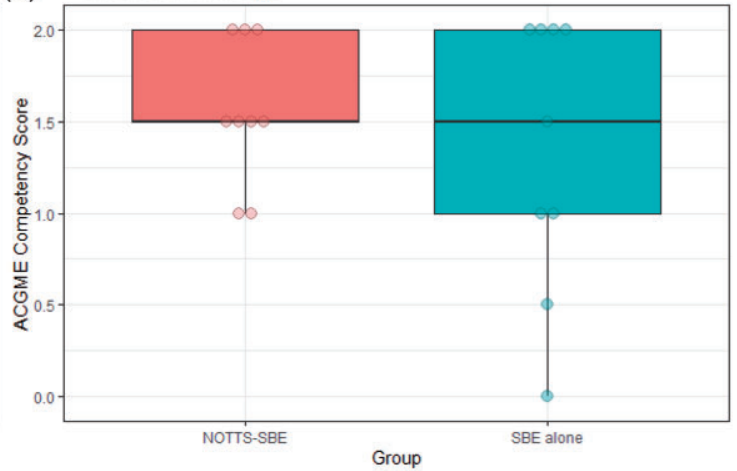

(d) Professionalism

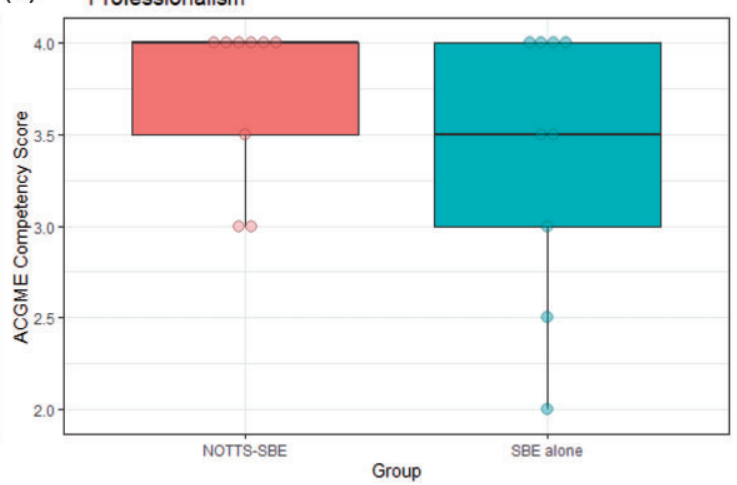

(f) System based learning

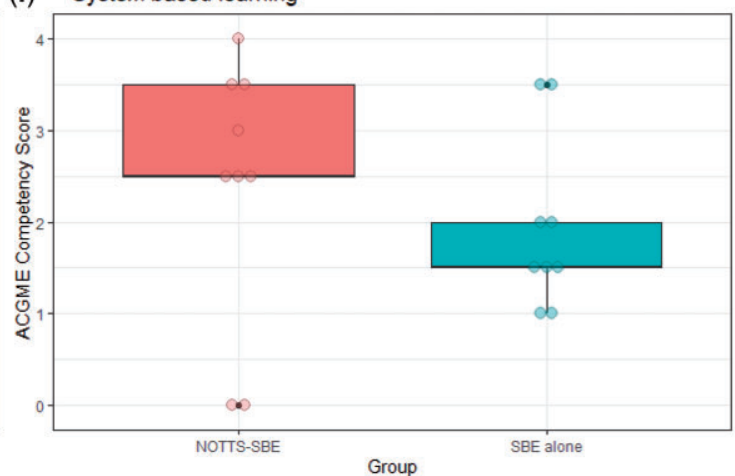

Figure 1. Difference in ACGME competencies among residents.

Table 4. ACGME competencies by PGY subgroups ( $N=18)$

\begin{tabular}{llll}
\hline ACGME competencies (maximum score) & PGY 1 and 2 (mean) & PGY 3 and 4 (mean) & P value \\
\hline Patient care (16) & $12.2(0.94)$ & $12.1(2.26)$ & 0.856 \\
Medical knowledge (2) & $1.25(0.64)$ & $1.69(0.46)$ & 0.125 \\
Interpersonal and communication skills (16) & $12.5(1.97)$ & $3.6(1.71)$ & 0.964 \\
Professionalism (4) & $3.45(0.73)$ & $1.69(0.46)$ & 0.556 \\
Practice-based learning and improvement (2) & $1.85(0.24)$ & $2.38(1.36)$ & 0.069 \\
System-based practice (4) & $2.00(1.13)$ & 0.501 & \\
\hline
\end{tabular}


and higher number of observable events may be necessary to have enough power to detect a statistically significant difference.

Other cofounding factors in this study included a long delay in the study due to the Coronavirus-19 pandemic. Less retention of skills in the intervention group may have changed the results of the study. Some of the later evaluation scenarios were done under the rules of social distancing, which could alter the efficacy of the teaching.

There was a trend toward high scores in the intervention group. Participants provided extremely positive feedback after the NOTSS and simulation-based education activities. Most participants reported an increase in confidence in all NTS especially the first year residents. They recommended that similar teaching sessions should be organized at the beginning of the residency program. For these reasons, the residency program is considering incorporating the NOTTS course in its simulation-based education curriculum. In addition, the evaluation form used is in line with the ACGME competencies; this may allow easy alignment of neck hematoma and NTS training with the ACGME surgical curriculum requirements. ${ }^{10,30}$

Simulation-based education has been successfully implemented in teaching for surgical residents. Common areas using simulation in general surgery training include laparoscopy and central line insertion. ${ }^{31-39}$ Our study indicates an additional use of simulation for general surgery training. This simulation-based education for neck hematoma can also be used to train a multidisciplinary team of providers, including surgeons, anesthesiologists, and nurses. The simulation scenario (Appendix 2) facilitates training of both technical and non-technical skills.

\section{Conclusions}

The results of this study did not show a statistically significant difference in the total performance scores on the six ACGME competencies among the two study groups. Therefore, this study failed to confirm our hypothesis that NOTSS methodology can improve ACGME competencies when combined with simulation-based education. A study with a bigger sample size and higher number of observable events may be necessary to have the power to detect a statistically significant difference. There was a trend toward high scores in the intervention group and positive feedback after the NOTSS and simulation-based education activities, therefore our residency program is considering incorporating the NOTTS course into its simulation-based education curriculum. In addition, there was a long delay in the study due to the Coronavirus-19 pandemic. Less retention of skills in the intervention group may have changed the results of the study. Some of the later evaluation scenarios were done under the rules of social distancing, which could alter the efficacy of the teaching.

\section{Conflicts of interest}

All authors declare no conflict of interest.

\section{References}

1. Gordon M, Derbyshire D, Baker P. Non-technical skills training to enhance patient safety. Clin Teach 2013; 10(3): 170175. https://doi.org/10.1111/j.1743-498X.2012.00640.x.

2. Flin R, O'Connor P, Crichton M. Safety at the sharp end: a guide to non-technical skills. Farnham, UK: Ashgate Publishing; 2017, p. 1-16.

3. Yule S, Flin R, Paterson-Brown S, Maran N. Non-technical skills for surgeons in the operating room: a review of the literature. Surgery 2006; 139(2): 140-149. https://doi.org/10. 1016/j.surg.2005.06.017.

4. Crossley J, Marriott J, Purdie H, Beard JD. Prospective observational study to evaluate NOTSS (Non-Technical Skills for Surgeons) for assessing trainees' non-technical performance in the operating theatre. Br J Surg 2011; 98(7): 1010-1020. https://doi.org/10.1002/bjs.7478.

5. Yule S, Rowley D, Flin R, Maran N, Youngson G, Duncan J, et al Experience matters: comparing novice and expert ratings of non-technical skills using the NOTSS system. ANZ J Surg 2009; 79(3): 154-160. https://doi.org/10.1111/j.14452197.2008. 04833.x.

6. Yule S, Flin R, Maran N, Rowley D, Youngson G, PatersonBrown S. Surgeons' non-technical skills in the operating room: reliability testing of the NOTSS behavior rating system. World J Surg 2008; 32(4): 548-556. https://doi.org/10.1007/s00268007-9320-z.

7. Yule S, Flin R, Maran N, Youngson G, Mitchell A, Rowley D, et al Debriefing surgical trainees on non-technical skills (NOTSS). Cogn Technol Work 2008; 10: 265-274. https://doi.org/10.1007/s10111-007-0085-9.

8. Flin R, Yule S, Paterson-Brown S, Maran N, Rowley D, Youngson G. Teaching surgeons about non-technical skills. Surgeon 2007; 5(2): 86-89. https://doi.org/10.1016/s1479666x(07)80059-x.

9. Higham $\mathrm{H}$, Baxendale B. To err is human: use of simulation to enhance training and patient safety in anaesthesia. Br J Anaesth 2017; 119(suppl 1): i106-i114. https://doi.org/10. 1093/bja/aex302.

10. Accreditation Council for Graduate Medical Education. ACGME Common Program Requirements (Residency). Available from: https://www.acgme.org/Portals/0/PFAssets/ 
ProgramRequirements/CPRResidency2019.pdf (accessed 26 September 2019).

11. Weiss A, Lee KC, Brumund KT, Chang DC, Bouvet M. Risk factors for hematoma after thyroidectomy: results from the nationwide inpatient sample. Surgery 2014; 156(2): 399-404. https://doi.org/10.1016/j.surg.2014.03.015.

12. Liu J, Sun W, Dong W, Wang Z, Zhang P, Zhang T, et al. Risk factors for post-thyroidectomy haemorrhage: a meta-analysis. Eur J Endocrinol 2017; 176(5): 591-602. https://doi. org/10.1530/EJE-16-0757.

13. Bononi M, Amore Bonapasta S, Vari A, Scarpini M, De Cesare A, Miccini $M$, et al. Incidence and circumstances of cervical hematoma complicating thyroidectomy and its relationship to postoperative vomiting. Head Neck 2010; 32(9): 1173-1177. https://doi.org/10.1002/hed.21313.

14. Rosato L, Avenia N, Bernante P, De Palma M, Gulino G, Nasi PG, et al. Complications of thyroid surgery: analysis of a multicentric study on 14,934 patients operated on in Italy over 5 years. World J Surg 2004; 28(3): 271-276. https://doi. org/10.1007/s00268-003-6903-1.

15. Hauch A, Al-Qurayshi Z, Randolph G, Kandil E. The importance of surgical volume on outcomes in thyroid surgery revisited: old is in again : editorial response to "what's old is new again" by Julie Ann Sosa (doi: 10.1245/s10434-014-3850z). Ann Surg Oncol 2014; 21(12): 3721-3722. https://doi. org/10.1245/s10434-014-3993-y.

16. Adam MA, Thomas S, Youngwirth L, Hyslop T, Reed SD, Scheri RP, et al.. Is there a minimum number of thyroidectomies a surgeon should perform to optimize patient outcomes? Ann Surg 2017; 265(2): 402-407. https://doi.org/10. 1097/SLA.0000000000001688.

17. Fan C, Zhou X, Su G, Zhou Y, Su J, Luo M, et al.. Risk factors for neck hematoma requiring surgical re-intervention after thyroidectomy: a systematic review and meta-analysis. BMC Surg 2019; 19(1): 98. https://doi.org/10.1186/s12893-0190559-8.

18. Farooq MS, Nouraei R, Kaddour H, Saharay M. Patterns, timing and consequences of post-thyroidectomy haemorrhage. Ann R Coll Surg Engl 2017; 99(1): 60-62. https://doi.org/10. 1308/rcsann.2016.0270.

19. Puskar K, Mitchell AM, Lee H, Kane I, Albrecht SA, Frank LR, et al. Simulated case studies illustrate interprofessional education for alcohol and drug use screening for healthcare professionals. ARC J Nurs Healthc 2016; 2(2): 9-20. https://doi.org/10.20431/2455-4324.0202002.

20. Luctkar-Flude M, Baker C, Pulling C, McGraw R, Dagnone D, Medves J, et al. Evaluating an undergraduate interprofessional simulation-based educational module: communication, teamwork, and confidence performing cardiac resuscitation skills. Adv Med Educ Pract 2010; 1: 59-66. https://doi.org/10. 2147/AMEP.S14100.
21. Yang LY, Yang YY, Huang CC, Liang JF, Lee FY, Cheng HM, et al. Simulation-based inter-professional education to improve attitudes towards collaborative practice: a prospective comparative pilot study in a Chinese medical centre. BMJ Open 2017; 7(11): e015105. https://doi.org/10.1136/bmjopen-2016-015105.

22. Hagemann V, Herbstreit F, Kehren C, Chittamadathil J, Wolfertz S, Dirkmann D, et al. Does teaching non-technical skills to medical students improve those skills and simulated patient outcome? Int J Med Educ 2017; 8: 101-113. https://doi.org/10.5116/ijme.58c1.9f0d.

23. Bruppacher HR, Alam SK, LeBlanc VR, Latter D, Naik VN, Savoldelli GL, et al. Simulation-based training improves physicians' performance in patient care in high-stakes clinical setting of cardiac surgery. Anesthesiology 2010; 112(4): 985992. https://doi.org/10.1097/ALN.0b013e3181d3e31c.

24. Zwaan L, Tjon Soei Len L, Wagner C, van Groeningen D, Kolenbrander M, Krage R. The reliability and usability of the Anesthesiologists' Non-Technical Skills (ANTS) system in simulation research. Adv Simul (Lond) 2016; 1: 18. https://doi.org/10.1186/s41077-016-0013-2.

25. Fletcher G, Flin R, McGeorge P, Glavin R, Maran N, Patey R. Anaesthetists' Non-Technical Skills (ANTS): evaluation of a behavioural marker system. Br J Anaesth 2003; 90(5): 580588. https://doi.org/10.1093/bja/aeg112.

26. Jung JJ, Borkhoff CM, Jüni P, Grantcharov TP. Non-Technical Skills for Surgeons (NOTSS): critical appraisal of its measurement properties. Am J Surg 2018; 216(5): 990-997. https://doi. org/10.1016/j.amjsurg.2018.02.021.

27. The Royal College of Surgeons of Edinburgh. NOTSS for surgeons. Available from: https://www.rcsed.ac.uk/professio nal-support-development-resources/learning-resources/non-tec hnical-skills-for-surgeons-notss/notss-for-trainees (accessed 26 September 2019).

28. Skelton T, Nshimyumuremyi I, Mukwesi C, Whynot S, Zolpys L, Livingston P. Low-cost simulation to teach anesthetists' non-technical skills in Rwanda. Anesth Analg 2016; 123(2): 474-480. https://doi.org/10.1213/ANE.0000000000001434.

29. Gwet K. Kappa statistic is not satisfactory for assessing the extent of agreement between raters. Statistical Methods for Inter-Rater Reliability Assessment, No. 1. 2002, p. 1-5.

30. Sachdeva AK, Pellegrini CA, Johnson KA. Support for simulation-based surgical education through American College of Surgeons-accredited education institutes. World J Surg 2008; 32(2): 196-207. https://doi.org/10.1007/s00268-007-9306-x.

31. American College of Surgeons (ACS) and the Association of Program Directors in Surgery (APDS) surgical skills curriculum for residents: phase II. https://learning.facs.org/content/acsapds-surgery-resident-skills-curriculum-phase-2 (accessed 8 June 2021).

32. Scott DJ, Dunnington GL. The new ACS/APDS skills curriculum: moving the learning curve out of the operating room. J 
Gastrointest Surg 2008; 12(2): 213-221. https://doi.org/10. 1007/s11605-007-0357-y.

33. Sánchez A, Rodríguez O, Benítez G, Sánchez R, De la Fuente L. Development of a training model for laparoscopic common bile duct exploration. JSLS 2010; 14(1): 41-47. https://doi. org/10.4293/108680810X12674612014464.

34. Scott DJ, Bergen PC, Rege RV, Laycock R, Tesfay ST, Valentine RJ, et al.. Laparoscopic training on bench models: better and more cost effective than operating room experience? J Am Coll Surg 2000; 191(3): 272-283. https://doi. org/10.1016/s1072-7515(00)00339-2.

35. Fried GM, Feldman LS, Vassiliou MC, Fraser SA, Stanbridge D, Ghitulescu G, et al. Proving the value of simulation in laparoscopic surgery. Ann Surg 2004; 240(3): 518-525; discussion 525-528. https://doi.org/10.1097/01.sla.0000136941.46529. 56.
36. Derossis AM, Antoniuk M, Fried GM. Evaluation of laparoscopic skills: a 2-year follow-up during residency training. Can J Surg 1999; 42(4): 293-296.

37. Sturm LP, Windsor JA, Cosman PH, Cregan P, Hewett PJ, Maddern GJ. A systematic review of skills transfer after surgical simulation training. Ann Surg 2008; 248(2): 166-179. https://doi.org/10.1097/SLA.0b013e318176bf24.

38. Sroka G, Feldman LS, Vassiliou MC, Kaneva PA, Fayez R, Fried GM. Fundamentals of laparoscopic surgery simulator training to proficiency improves laparoscopic performance in the operating room-a randomized controlled trial. Am J Surg 2010; 199(1): 115-120. https://doi.org/10.1016/j.amjsurg.2009.07.035.

39. Barsuk JH, McGaghie WC, Cohen ER, O'Leary KJ, Wayne DB. Simulation-based mastery learning reduces complications during central venous catheter insertion in a medical intensive care unit. Crit Care Med 2009; 37(10): 2697-2701. 


\section{Appendix 1: Data collection tool: residents' performance according to ACGME competencies}

Film number:

Rater number :

\begin{tabular}{|c|c|c|c|c|}
\hline \multirow[t]{2}{*}{ ACGME Competencies } & \multirow{2}{*}{$\begin{array}{l}\text { Target actions: } \\
\text { Resident has }\end{array}$} & \multicolumn{3}{|c|}{ Resident performance } \\
\hline & & $\begin{array}{l}\text { Hit } \\
2\end{array}$ & $\begin{array}{l}\text { Hit after } \\
\text { prompting } 1\end{array}$ & $\begin{array}{l}\text { Missed } \\
0\end{array}$ \\
\hline \multicolumn{5}{|c|}{ Step1: Identification of posthyroidectomy hematoma } \\
\hline \multirow{2}{*}{$\begin{array}{l}\text { Interpersonal and } \\
\text { communication skills }\end{array}$} & 1. Performed introductions & & & \\
\hline & 2. Received handover & & & \\
\hline \multirow[t]{2}{*}{ Patient care } & 3. Performed focused physical exam of the neck & & & \\
\hline & 4. Identified hematoma & & & \\
\hline \multirow{2}{*}{$\begin{array}{l}\text { Interpersonal and } \\
\text { communication skills }\end{array}$} & 5. Called for help (Anesthesiologist and Surgeon) & & & \\
\hline & 6. Called for resuscitation cart & & & \\
\hline Medical knowledge & $\begin{array}{l}\text { 7. Informed team (nurse, anesthesiologist, and } \\
\text { surgeon) about the management plan }\end{array}$ & & & \\
\hline \multicolumn{5}{|c|}{ Step 2: Management of posthyroidectomy hematoma } \\
\hline \multirow[t]{6}{*}{ Patient care } & 8. Removed dressing and Steristrips & & & \\
\hline & 9. Released skin sutures & & & \\
\hline & 10. Released deep sutures & & & \\
\hline & 11. Evacuated hematoma & & & \\
\hline & 12. Placed temporary packing & & & \\
\hline & 13. Considered intubation & & & \\
\hline \multirow{4}{*}{$\begin{array}{l}\text { Interpersonal and } \\
\text { communication skills }\end{array}$} & 14. Informed OR of take back & & & \\
\hline & $\begin{array}{l}\text { 15. Exchanged information with the team when the } \\
\text { patient's oxygen saturation dropped }\end{array}$ & & & \\
\hline & $\begin{array}{l}\text { 16. Worked effectively with the team when the } \\
\text { patient's oxygen saturation dropped }\end{array}$ & & & \\
\hline & $\begin{array}{l}\text { 17. Listened attentively to the stated needs of } \\
\text { information provided by the team during the crisis }\end{array}$ & & & \\
\hline \multirow[t]{2}{*}{ Professionalism } & 18. Informed the Attending Surgeon of situation & & & \\
\hline & $\begin{array}{l}\text { 19. Demonstrated respect and sensitivity to } \\
\text { anesthesia regarding desaturation during difficult } \\
\text { airway management (if applicable) }\end{array}$ & & & \\
\hline
\end{tabular}

Step 3: Plan safe transfer of the patient to OR for definitive hemostasis

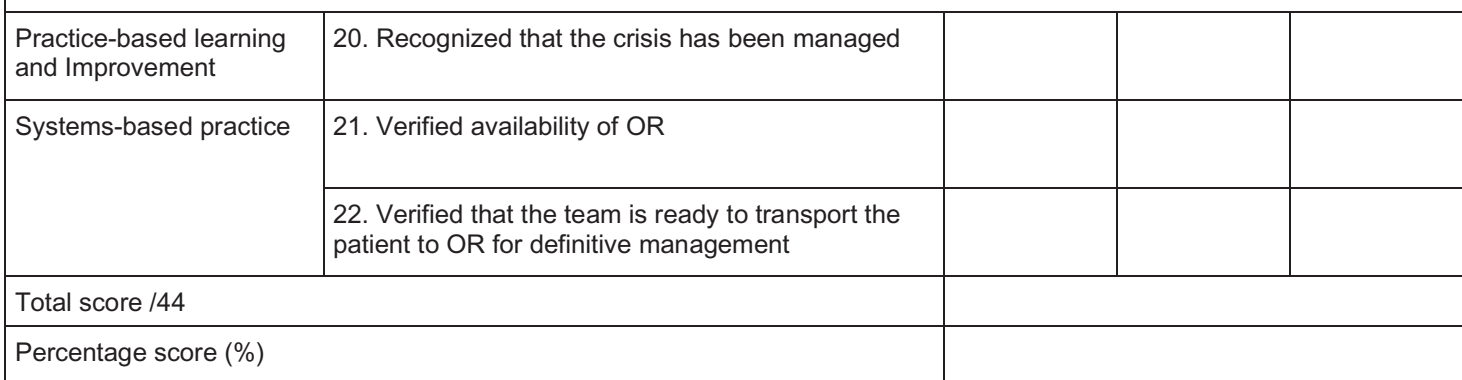

\section{Appendix 2: simulated scenario}

See supplementary material. 